\title{
Shear Behavior of RC Deep Beam Strengthened by V-Shaped External Rods
}

\author{
Pramod Rai, Kitjapat Phuvoravan* \\ Department of Civil Engineering, Kasetsart University, Jatujak, Bangkok, Thailand \\ Received 30 April 2019; received in revised form 29 May 2019; accepted 07 August 2019 \\ DOI: https://doi.org/10.46604/ijeti.2020.4174
}

\begin{abstract}
This research investigated the shear strengthening technique of Reinforced Concrete (RC) deep beams using a V-shaped external rod system. Shear behavior, the stress in an external rod, and the shear capacity at the diagonal shear failure of a strengthened beam were focused mainly. Experimental tests of control and two strengthened beams were carried out to observe the effect of the external rod on shear behavior of RC deep beam. A theoretical approach to compute the stress in the external rod and the nominal strength of the strengthened beam in the diagonal shear failure were examined based on the experimental test results and verified using Finite Element Method (FEM) in ABAQUS. The computed nominal shear strength of the strengthened beam was $10 \%$ higher than the experimental test. The strengthening technique shifted the brittle shear failure to ductile shear failure and improved the performance of RC deep beam.
\end{abstract}

Keywords: external posttension technique (EPT), nonlinear finite element, experimental investigation, shear strengthening, reinforced concrete deep beam, strut-and-tie model (STM)

\section{Introduction}

Several techniques have been investigated for strengthening of reinforced concrete (RC) beams, including External Post-Tension (EPT) [1-4], Fiber Reinforced Polymers (FRP) [5-6], Bolted-Steel Plate (BSP) [7], and concrete jacketing [8]. Each method has its own merits and demerits. Recently, the use of FRP has gained popularity due to it being lightweight, easy to install and having aesthetic preservation and high-tensile strength; however, the strengthened structure can experience several failure modes due to the premature debonding of the composites from the concrete surface [9]. Similarly, BSP into the concrete portion of the beam not only reduces the effective cross-sectional area of the beam but also results in the formation of cracks and disrupts the integrity of the materials; as a result, the concrete section does not achieve its full strength [10-11]. Compared to these methods, the EPT technique offers certain advantages, mainly it provides active force from the beginning of the external loading stage if sufficient prestressing is provided. However, it can create aesthetic and operational concerns if not properly covered [4].

An EPT system mainly consists of two different methods: post-tensioning using seven-wire strands and using rods or tendons. In the prior method, a hydraulic jack is used to provide tension on the wire which requires sufficient operational space. In the later, the unbonded external rods or tendons are anchored at the ends of the RC beam and post-tensioned by anchor wedges or turnbuckles. The important issue with this technique is that the yielding of the unbonded rod or tendon is not achieved during the failure stages unless sufficient initial pretension is applied [1-4].

A substantial number of researchers have investigated the flexural strengthening of RC beams using external rods or tendons [1-4]. Harajli [1] performed experimental tests of EPT beams and found the draped profile relatively more effective

* Corresponding author. E-mail address: fengkpp@ku.ac.th 
than straight profile tendons in flexural strengthening. Shin et al. [2] examined multiple RC beams strengthened using V-and $\mathrm{U}$-shaped external rods using two deviators and found that the U-shaped rods were more effective than the V-shaped ones in flexural strengthening. Shin and Lee [3] studied the flexural strengthening using a V-shaped profile and observed that the specimens with minimum prestressing of $40 \%$ of the yield strength of external rods had the maximum strain surpassing the yield strain of the steel rod at ultimate flexural failure. Taking account of the minimum prestressing $40 \%$ of the yield strengths of the external rods, Shin, Lee, and Kang proposed analysis and design methods for an EPT beam with a rectangular section at yield and the ultimate stage for both shored and unshored beams [4]. Lee, Shin, and Lee [12] further investigated the damage of EPT beam due to repetitive loading and concluded that the method was effective in controlling crack width and re-establishing the service load deflections of the beams. Many other researchers have focused on the determination of the stress generated in the external rod during the ultimate flexural failure of the strengthened beam [13-14].

Though considerable research has been carried out to investigate the flexural behavior of EPT beams, investigations on shear strengthening are limited, though the study of shear strengthening techniques is equally important as the structures fail instantly without warning due to shear failure. Most importantly, the RC beams with a shear-span-to-depth ratio (a/h) less than two and subjected to shear force, are susceptible to shear failure. Sirimontree et al. [15] studied the shear strengthening of an $\mathrm{RC}$ beam using a transverse external post-tension rod and observed enhancements in the load carrying capacities of all the strengthened beams. The external rods used in the investigation were placed in a vertical direction using top and bottom steel plates and post-tensioned by tightening the nuts. Sirimontree et al. further recommended the use of a strut and tie model for conservative prediction of the ultimate shear capacity of a strengthened beam [15]. Lee et al. [16] adopted some test specimens which exhibited shear failure, and not flexure failure, from specimens of their previous research investigation and studied the generated stress of a V-profile high-strength external rod system in continuous RC beams. The unbonded external rods used in the strengthened beam did not yield at the failure stage during the test; thus the researchers developed an analytical approach to compute the stress on the external rods at the diagonal shear failure stage [16]. Due to the high shear-span-to-effective-depth ratio $(\mathrm{a} / \mathrm{d}>2.5)$ of the beams, Zsutty's theoretical equation [17] was adopted to determine the shear strength of concrete in the research.

As there have been very limited efforts made to investigate shear strengthening of RC beams using a V-shaped external rod system, this research focused on the examination of the shear behavior, computation of the generated stress in the external rod, and prediction of the shear capacity of the strengthened beam at the diagonal shear failure stage. Previous research on continuous beams with $\mathrm{a} / \mathrm{d}>2.5$ indicated the possible use of a $\mathrm{V}$-shaped rod in shear strengthening [16]. Therefore, in this research, the shear structural behavior of the experimentally tested RC beam specimens strengthened with V-shaped external rods were compared with the behavior of a reference beam. Finite element analysis (FEA) of one of the tested beam specimens was simulated using the Finite Element Method (FEM)-based software package, ABAQUS, to determine the stress generated in the external rod during the diagonal shear failure. An analytical approach to compute the stress on the external rod was used to examine the beam configuration used in this research, and finally, a theoretical method was recommended that predicted the nominal shear strength close to the experimental test.

\section{Materials and Methods}

\subsection{Experimental test overview and methodology}

Experimental tests of the RC beam specimens were carried out to investigate the effect on shear behavior due to V-shaped external rods. The beam specimens were applied with two-point static vertical loading using a hydraulic jack and load cell at a span of $1 \mathrm{~m}$, maintaining $\mathrm{a} / \mathrm{h}<2$. The applied load was recorded throughout the experiment using the sensors built into the load cell, and the mid-span deflections were recorded using a linear variable differential transformer. Strain gauges were installed at the main longitudinal reinforcement, web reinforcement, and external rods to measure the strains. The prestress force on the 
external rods was applied manually through turn-buckles before the application of vertical load and strains were measured at four different locations of a rod. Loads at the initiation of cracks were observed and recorded manually. Crack patterns were recorded using a digital camera during the test and failure modes based on the crack patterns were analyzed after the completion of the test.

\subsection{Material test results}

Laboratory tests of the materials used in the specimens were performed to determine their mechanical properties. The compressive strength of concrete was determined by testing cylinders at the age of 28 days. High carbon steel (characterized by high yield and ultimate strength and low elongation ratio) was used for the external tensioning rods. The stress-strain curve of the high tension external rod obtained from laboratory testing is shown in Fig. 1. The overall test set up and the configurations of beam specimens are shown in Figs. (2)-(4). The specifications of the materials used in the specimens are shown in Table 1.

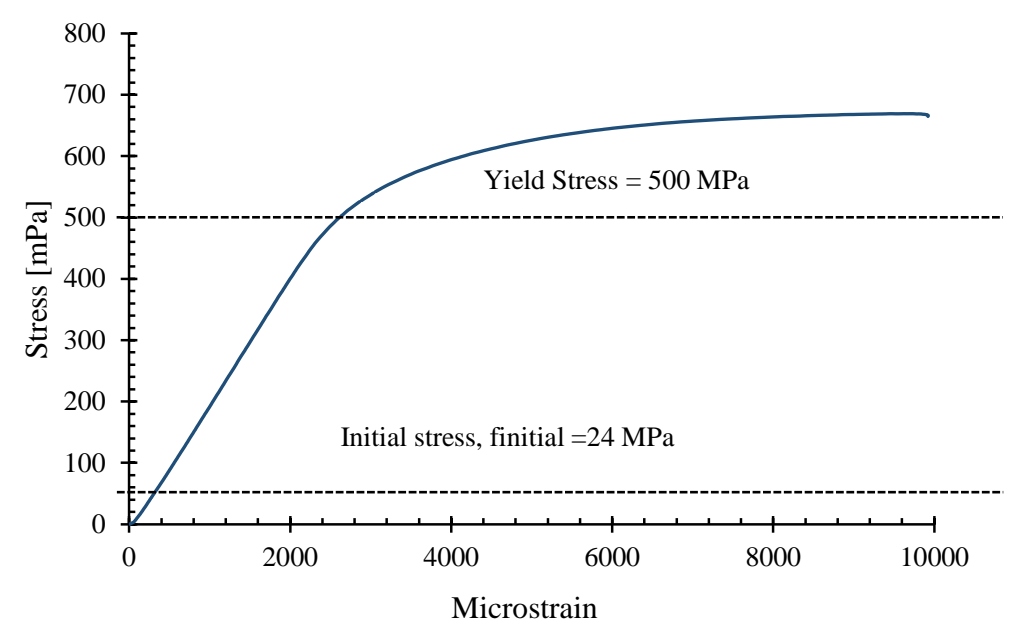

Fig. 1 Stress-Strain curve of external post-tension rod obtained from experimental test

Table 1 Summary of Material Properties

\begin{tabular}{|c|c|c|c|}
\hline Material & Diameter [mm] & Yield Strength [MPa] & Elastic Modulus [GPa] \\
\hline Web Reinforcement & R9 & 236 & 200 \\
\hline Top Bar & D12 & 392 & 200 \\
\hline Bottom Bar & D16 & 392 & 200 \\
\hline External Posttension Rod & HC19 & 500 & 203 \\
\hline Anchorage Steel & R60 & 392 & 2,100 \\
\hline Concrete & $\mathrm{F}_{\mathrm{c}}{ }^{-}=17.58 \mathrm{MPa}$ & \multicolumn{2}{|c|}{$\mathrm{E}_{\mathrm{c}}=22,655.33 \mathrm{MPa}$} \\
\hline
\end{tabular}

\subsection{Detail of beam specimens}

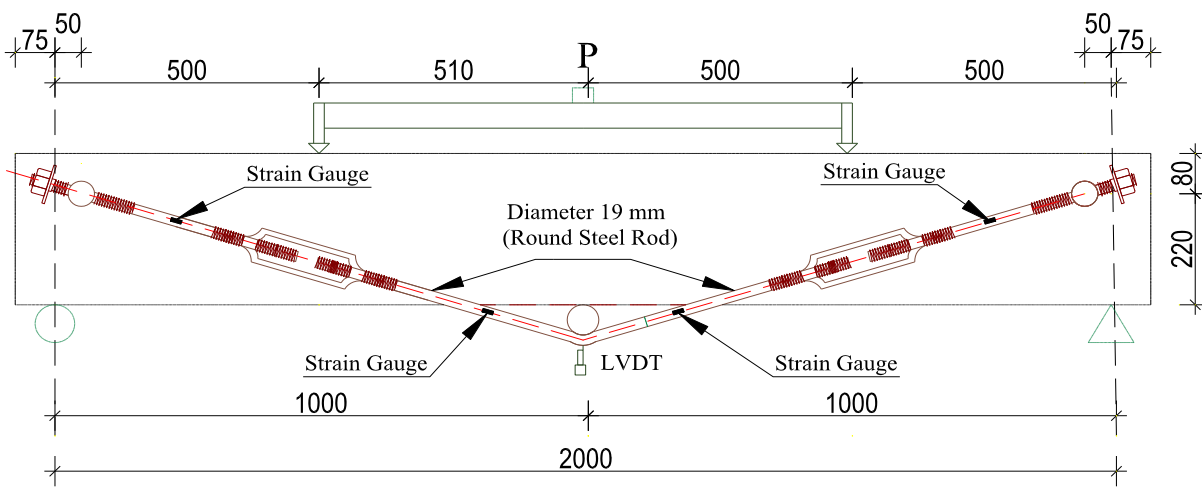

Fig. 2 Specimen dimensions and experimental set up (units in $\mathrm{mm}$ )

For the experimental test, three RC beam specimens of the identical section were cast using ready-mix concrete. The beam specimens designed with the minimum shear reinforcement recommended in the standard ACI 318-14 were expected to fail by 
shear failure mode. The geometric details of the beam specimens are shown in Figs. (2)-(4). All the beam specimens were provided with 2-12 $\mathrm{mm}$ top bars, 3-16 mm bottom bars, and $9 \mathrm{~mm}$ stirrups spaced at $135 \mathrm{~mm}(\mathrm{~d} / 2)$. The external rods of $19 \mathrm{~mm}$ diameter were installed in two strengthened specimens, after the curing stage as shown in Fig. 2. The Control Beam (CB) was used as the reference to compare the effects in structural behavior. The beam specimens strengthened with V-shaped rods were labeled as SB0 and SB1. The data from beam specimens were used for the analysis and for the investigation of the crack patterns and failure modes.

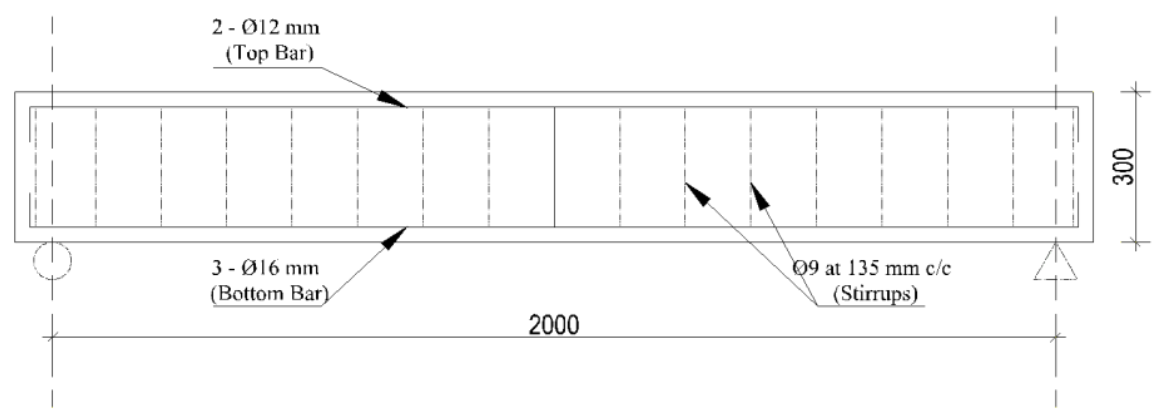

Fig. 3 Longitudinal reinforcement detail (units in $\mathrm{mm}$ )

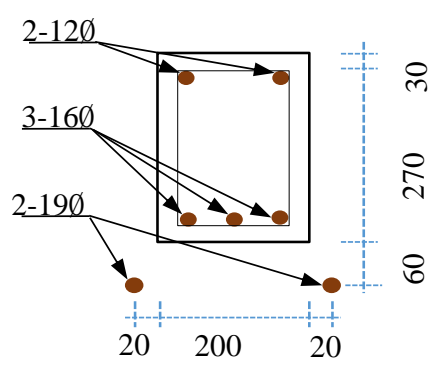

Fig. 4 Beam cross-section details (the two external rods were present in SB0 and SB1 but not in CB) (units in $\mathrm{mm}$ )

\section{Experimental Test Results and Discussions}

\subsection{Overall description of the experiment}

The initial stress on the external rods of the strengthened beam specimens was applied by tightening turn-buckles manually by hands. Before the application of load, the initial prestress applied to the external rod was $24 \mathrm{MPa}\left(0.05 \mathrm{f}_{\mathrm{EPTy}}\right)$. This was the maximum prestress the researchers could apply manually. The displacement in the strengthened beam was measured after application of prestressing force.

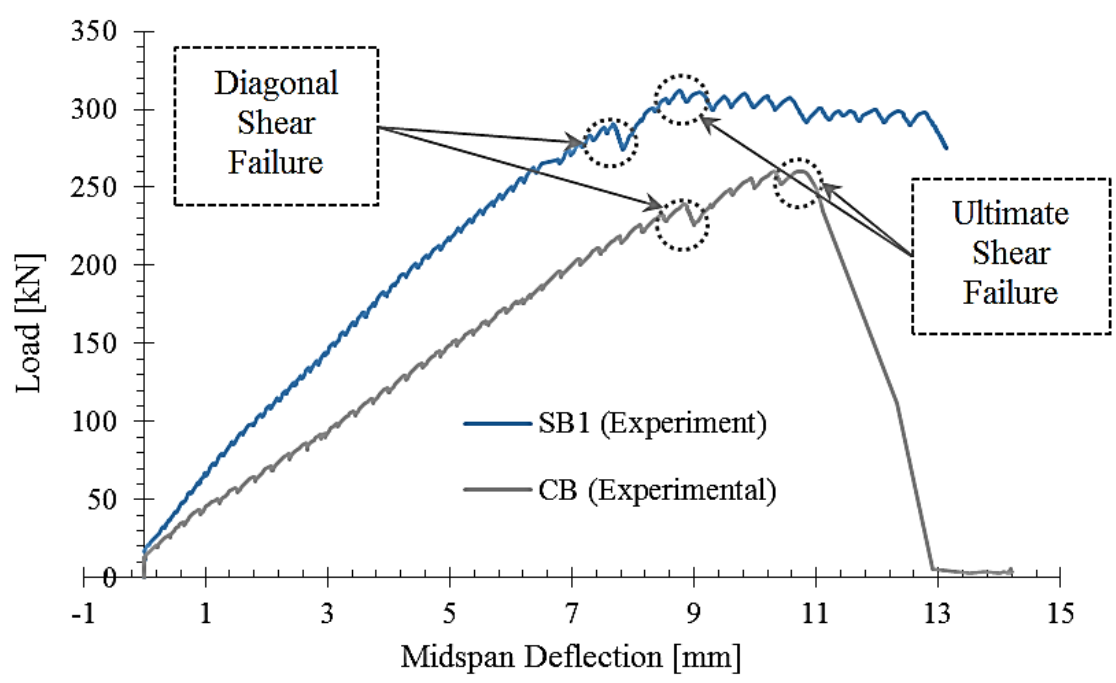

Fig. 5 Experimental load-midspan deflection curves for specimens CB and SB1 
The structural behavior of the tested specimens was analyzed based on the load-midspan deflection relationship, ultimate load carrying capacity, stiffness, ductility, and failure mode. As expected, all the beam specimens failed in diagonal shear failure mode. The beam specimens failed earlier than the yielding of the longitudinal reinforcement; therefore, the ductility parameter in this study was defined in terms of the deformation ratio, the ratio of the mid-span deflection of the control beam to the deflection of the strengthened beam at their respective ultimate loading stages. The stiffness of the control beam was obtained from the slope of the load-to-midspan deflection curve at the diagonal shear failure; and for the strengthened beam, it was obtained at a deflection equal to the ultimate deflection of the control beam. The load-midspan deflection curves of the two beam specimens, CB and SB1, are shown in Fig. 5.

\subsection{Control beam specimen $(C B)$}

The sudden fall of the stiffness in the load-midspan deflection curve in Fig. 5 indicates that the beam specimen CB failed in brittle nature right after the ultimate loading stage. The propagation of diagonal shear cracks and the failure are displayed in Fig. 6. The diagonal shear failure and the ultimate failure occurred at loads of $239.14 \mathrm{kN}$ and $260.43 \mathrm{kN}$, respectively. The midspan deflections at such stages of loadings were $8.86 \mathrm{~mm}$ and $10.74 \mathrm{~mm}$, respectively. Such kind of additional load carrying capacity, after the initiation of diagonal shear cracks, is referred as the reserve load capacity which, in terms of STM perspective, is referred as the arc action of RC deep beams.

Fig. 6 shows the crack at the ultimate failure cracks of CB. The failure began from the initiation of a diagonal crack in the diagonal compression strut at the proximity of the neutral axis of the beam section and propagated more towards the tensile zone (C-C-T node). Minimum presence of shear reinforcement, the dominance of shear force, and relatively lower a/h ratio were the reasons behind the manifestation of such failure. Compared to the compression zone, high concentration of cracks with wider widths were observed in the tensile zone, as shown in Fig. 6. The measured crack width of in compression and tension zone were approximately $2 \mathrm{~mm}$ and $3.5 \mathrm{~mm}$, respectively. The critical shear crack that caused the diagonal shear failure of $\mathrm{CB}$ is shown in Fig. 7. The approximate inclination of the diagonal cracks on the $\mathrm{CB}$ was $45^{\circ}-50^{\circ}$, as shown in Fig. 8 . However, much fewer flexural cracks were formed in CB throughout the experimental test.

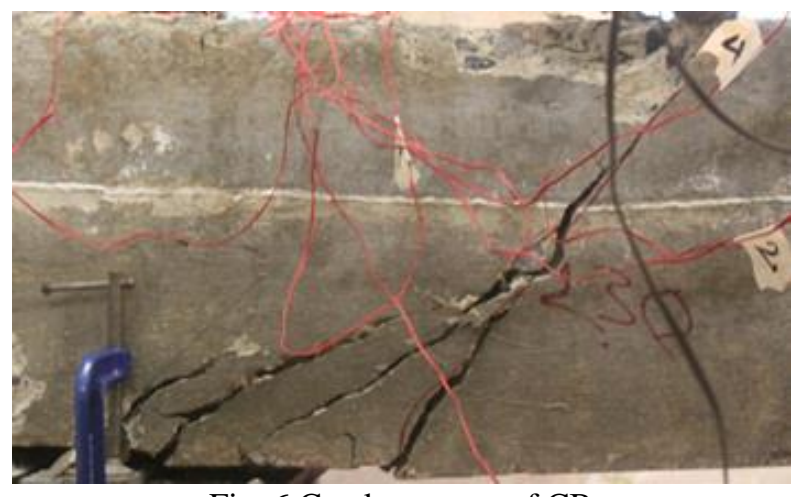

Fig. 6 Crack patterns of $\mathrm{CB}$

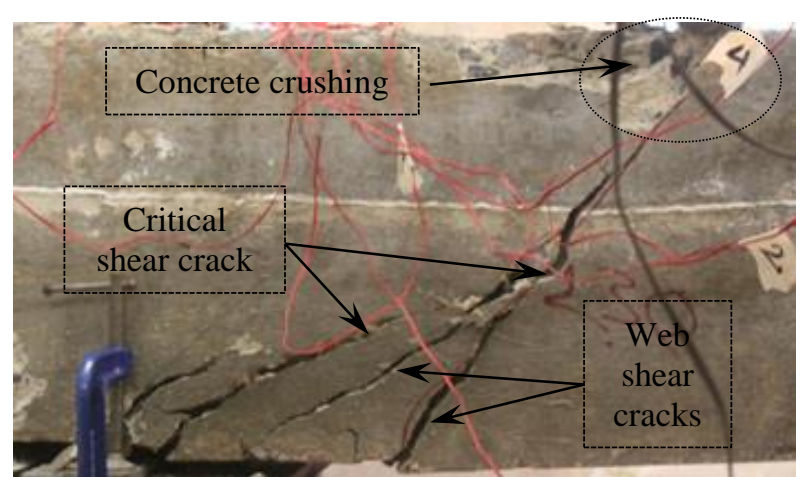

Fig. 7 Cracks in $\mathrm{CB}$ at ultimate failure

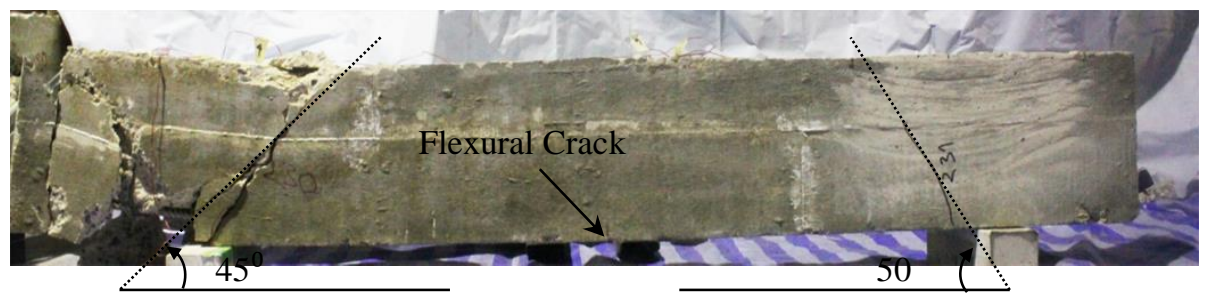

Fig. 8 Inclination of crack pattern in $\mathrm{CB}$

\subsection{Strengthened beam specimens ( $S B O$ and $S B 1)$}

The beam specimens SB0 and SB1 were two identical specimens strengthened using V-shaped external rods of 19 mm. 
The failure pattern and the damage occurred in the shear zone of SB0 is shown in Fig. 9, and the inclination of the cracks are shown in Fig. 10. The load-midspan deflection graph of SB1 is included in Fig. 5. Unlike the CB, the load-midspan deflection response of SB1 didn't drop suddenly after ultimate loading stage, suggesting that the strengthened beam specimen exhibited ductile shear failure. The diagonal shear failure and the ultimate shear failure of SB1 occurred at $290.19 \mathrm{kN}$ and $311.56 \mathrm{kN}$, respectively, and the corresponding midspan deflections were $7.69 \mathrm{~mm}$ and $8.77 \mathrm{~mm}$. The tensile forces generated in the inclined posttenion rods contributed to reducing the diagonal tensile stresses, thereby increasing the shear capacities, at all loading stages.

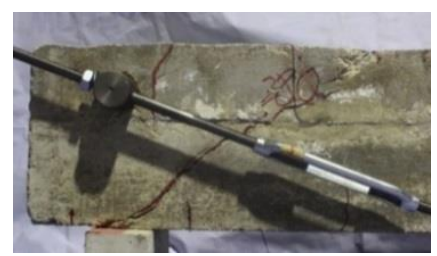

Fig. 9 Crack patterns of SB0

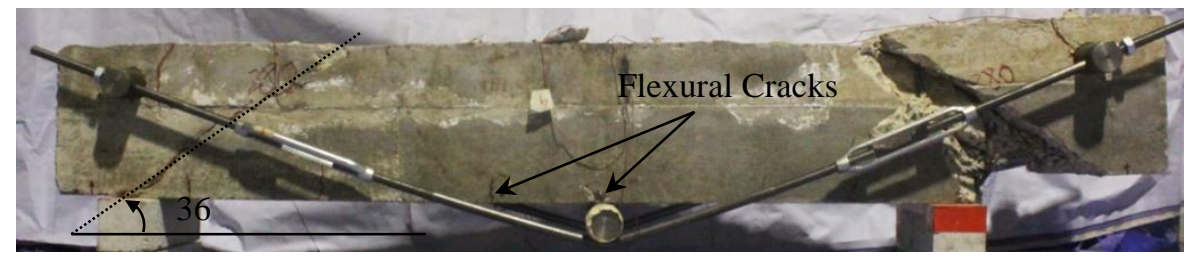

Fig. 10 Inclination of crack pattern in beam specimen SB0

Both the strengthened beam specimens demonstrated nearly similar mechanism as demonstrated by CB, that is, by the initiation of a diagonal crack in the diagonal compression strut at the proximity of neutral axis, at the relatively higher loading stage. However, unlike the case of $\mathrm{CB}$, the diagonal shear cracks propagated along both the compression and tension zones, running from the loading point to the support, until the beam failed by crushing of the concrete in the vicinity of the loading point. With an increase in external load, the compressive stress transferring from the inclined rod interacted with the vertical shear stress thereby increasing the principal stress responsible for the crushing of concrete in the compression zone. The failure pattern and the damage occurred in the shear zone of SB1 are shown in Fig. 11 and the critical shear crack that caused the diagonal shear failure is shown in Fig. 12. Similarly, the inclination of the crack is shown in Fig. 13. In general, the inclination of the diagonal crack in the strengthened beam specimens was in the range of $36^{\circ}-43^{\circ}$. Such decrease in the inclination of the diagonal crack in SB0 and SB1 with respect to $\mathrm{CB}$ was due to the presence of compressive stress transferring from the external rods to the concrete and its interaction with the shear stress upon loading. The combined action lowered the maximum principal stress angle with respect to the vertical axis. The diagonal shear cracks completely traversed the beam sections until they failed by crushing of the concrete at the tip of the compression zone. At ultimate loading stages, the crack widths in both the tension and compression zones were observed for approximately $2.5-4 \mathrm{~mm}$ in both specimens. Until ultimate failure, a minimal number of flexural cracks were observed in these beam specimens too.

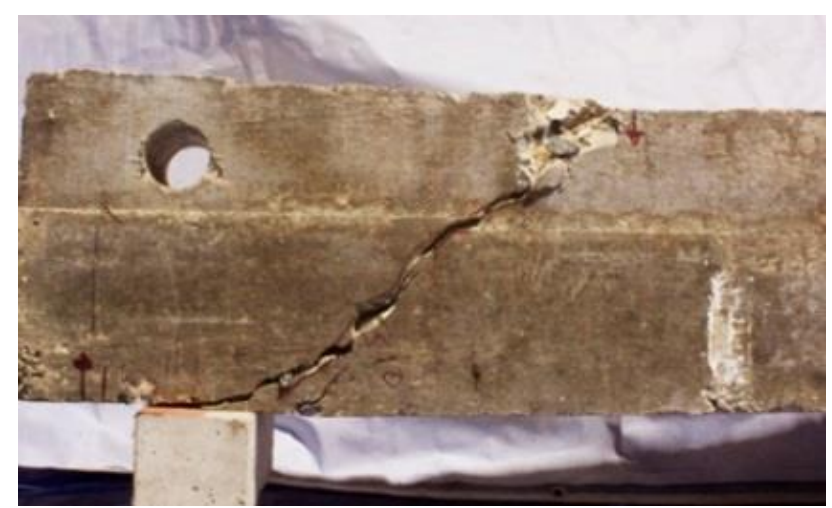

Fig. 11 Crack patterns of CB

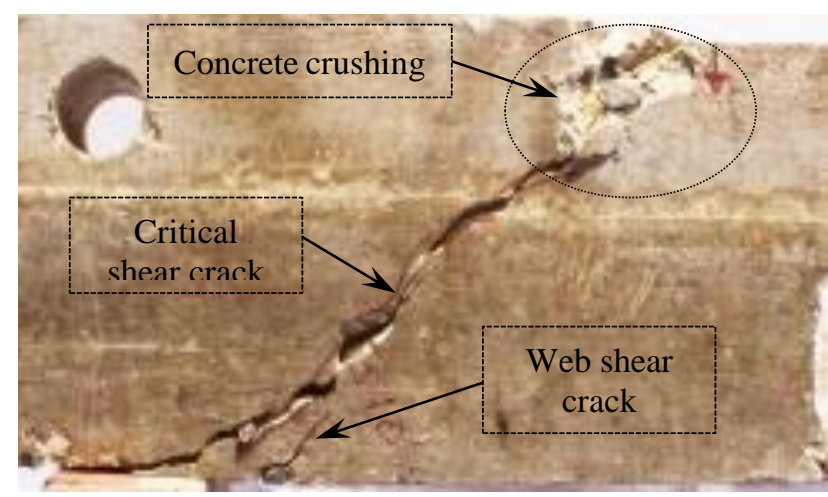

Fig. 12 Cracks in SB1 at ultimate failure 


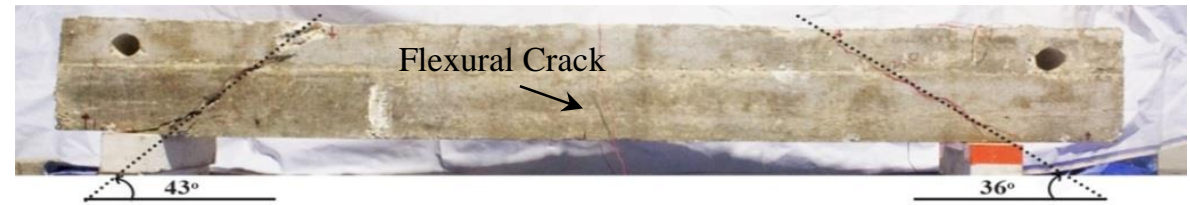

Fig. 13 Inclination of crack pattern in beam specimen SB1

Overall, the direct effect of an unbounded external rod can be observed in the load-to-midspan deflection displayed in Fig. 5. The control beam specimen failed in a brittle manner, whereas the strengthened beam specimen showed shear ductile behavior. Fig. 5 shows improvement in the load carrying capacity of the strengthened beam in all stages. The diagonal shear failure of CB and SB1 occurred when the imposed loads were $239.14 \mathrm{kN}$ and $290.19 \mathrm{kN}$, respectively, indicating a $21 \%$ improvement. Similarly, the ultimate load carrying capacities of CB and SB1 were $260.43 \mathrm{kN}$ and $311.56 \mathrm{kN}$, respectively, indicating an improvement of $20 \%$ capacity at the ultimate stage. Prior to the diagonal shear failure, the slope of the load-to-midspan deflection curve of SB1 was higher than CB, suggesting higher stiffness of SB1. The displacements in the diagonal shear failure stage of CB and SB1 were $8.86 \mathrm{~mm}$ and $7.69 \mathrm{~mm}$, respectively, which indicated a decrease in the displacement of the strengthened beam specimen by 15\%. Likewise, the displacement of CB and SB1 at ultimate failure loads were $10.74 \mathrm{~mm}$ and $8.77 \mathrm{~mm}$, respectively, indicating their deformation ratio of 1.23 . Furthermore, the load to midspan deflection curves illustrated the shift in failure mode from brittle to ductile nature. A similar change in the nature of the failure was reported in earlier research in which the post-tensioning was applied through transverse PC strands, anchored by steel plates at the top and the bottom faces of the beam over the shear span [15]. The tensile forces from the external rod contributed to an improvement in the strength, stiffness, and ductility of the strengthened beam specimens. The diagonal cracks propagated and traversed along the entire section of the strengthened beams. While transferring the applied transverse loads from loading points to the supports, the principal tensile stresses or the diagonal tensile stresses were generated in the shear zone of the beams. The tensile stresses in the external rods contributed to reducing the diagonal tensile stresses and assisted in the improvement of the load carrying capacity of the strengthened beam.

\section{Finite Element Analysis (FEA)}

\subsection{Experimental beam model in ABAQUS}

Non-linear Finite Element Analysis (FEA) of the beam specimen SB1 was performed using the commercial software package ABAQUS. The main objectives of the analysis were to observe the strain distribution in the concrete and the depth of the neutral axis and to investigate the accuracy of the theoretically computed stress in the external rod at the diagonal shear failure loading stage. A full-fletched 3D model of the beam specimen used in the experimental test that was simulated in ABAQUS is shown in Fig. 14.

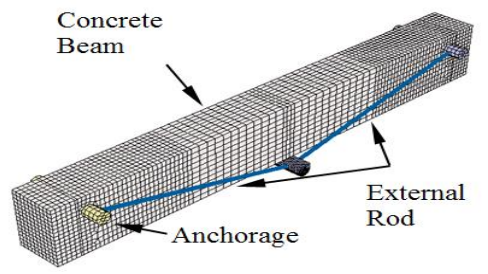

Fig. 14 3D Model of beam specimen SB1

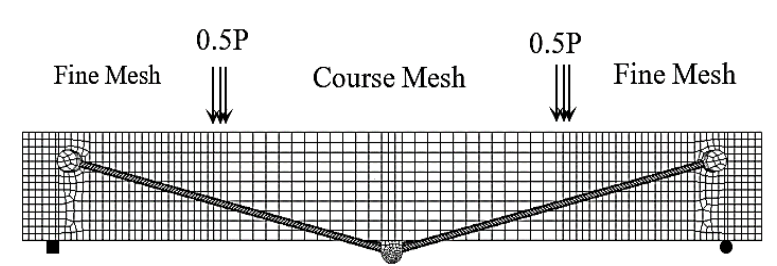

Fig. 15 Types of mesh sizes adopted in the model

\subsection{Element type and meshing scheme}

In this study, steel reinforcement and external posttension rod were modeled using a 2-node truss element (T3D2), and the concrete and anchorages were modeled using an 8-node solid finite element (C3D8). The total number of concrete, anchorage, longitudinal reinforcement, web reinforcement, and EPT rod elements were 10680, 663, 500, 570, and 4, respectively. External rods were meshed by number due to constraint issue. Figs. (14)-(15) show the meshing schemes assigned in the model. Two 
types of mesh sizes were assigned for the concrete elements with each element size of $40 \mathrm{~mm} \times 20 \mathrm{~mm} \times 20 \mathrm{~mm}$ and $20 \mathrm{~mm}$ $\times 20 \mathrm{~mm} \times 20 \mathrm{~mm}$, with the latter being assigned in the locations of interests. After several trials, the mesh sizes and locations as such were adopted to reduce the computation time with minimal compromise in the output results. Besides the periphery of holes made for anchorages, where the default meshing technique was used, a structured meshing technique was assigned for the concrete. The element sizes of reinforcement, both longitudinal and web, were $20 \mathrm{~mm}$. The anchorage mesh size was 20 $\mathrm{mm} \times 20 \mathrm{~mm} \times 20 \mathrm{~mm}$.

\subsection{Bonding between reinforcement and concrete, anchor and EPT rods, and anchor and concrete}

The steel reinforcements were embedded in the concrete. Thus, the translation degrees of freedom of the embedded node (reinforcements) are constrained to the interpolated values of the corresponding degrees of freedom of the host element [18].

The external rods were embedded in the anchor 3-D solid elements, thereby constraining the translation degrees of freedom of the rods to the anchorages. The external rods were assigned with a single element to embed the end nodes inside the anchorage. This allowed the transfer of stresses, strains, and forces from anchorages to the rods. The contact between the surfaces of the anchorages, including the bottom anchorage, and concrete were assigned as tie-constrained. A surface-based tie constraint in ABAQUS made the translational and rotational motion as well as all other active degrees of freedom equal for a pair of surfaces [18].

\subsection{Material modeling}

Two types of modeling techniques are available for concrete modeling in ABAQUS: a smeared crack model and a Concrete Damaged Plasticity (CDP) model [18]. According to the ABAQUS manual, the first model can be used for models subjected to monotonic straining, whereas the later can be applied in monotonic and/or cyclic loading. Several studies of this kind have been conducted successfully in the past based on a CDP model [19]. Therefore, the CDP model was used for the concrete in this research. The CDP model of concrete required the concrete compressive and tensile constitutive relationship, cracking and crushing damage parameters, and other various parameters [18]. The various parameters obtained from several trials and adopted in this research are shown in Table 2.

Table 2 CDPM Parameters

\begin{tabular}{|c|c|c|c|c|}
\hline Dilation Angle & Eccentricity & $\mathrm{F}_{\mathrm{bo}} / \mathrm{F}_{\mathrm{co}}$ & $\mathrm{K}$ & Viscosity \\
\hline 27.5 & 0.1 & 1.12 & 0.667 & 0.0005 \\
\hline
\end{tabular}

Though a concrete mix is composed of coarse aggregate, sand, cement, and water, it is considered as homogeneous material at the macro level in FEA. The uniaxial compressive strength of concrete obtained from a laboratory test was used $\left(f_{c}^{\prime}=17.58 \mathrm{MPa}\right)$. The strain of concrete $\varepsilon_{c}=0.002$ and $\varepsilon_{u}=0.0038$, corresponding to the compressive strength of $f_{c}^{\prime}$ and ultimate strain, respectively, were used and, the Poisson ratio used for the concrete was $v=0.18$. The modulus of elasticity obtained from the experimental test was used $\left(E_{c}=22,655.33 \mathrm{MPa}\right)$. The constitutive model for concrete proposed by Hongestad [20] was used in compression as shown in Eqs. (1)-(2):

$$
\begin{aligned}
& \sigma=\sigma_{0}\left[2\left(\frac{\varepsilon}{\varepsilon_{0}}\right)+\left(\frac{\varepsilon}{\varepsilon_{0}}\right)^{2}\right] \quad \text { if } \varepsilon \leq \varepsilon_{0} \\
& \sigma=\sigma_{0}\left[1-0.15\left(\frac{\varepsilon-\varepsilon_{0}}{\varepsilon_{u}-\varepsilon_{0}}\right)\right] \quad \text { if } \varepsilon_{0}<\varepsilon<\varepsilon_{u}
\end{aligned}
$$

where $\sigma_{0}=f_{c}^{\prime}, \varepsilon_{0}=2\left(\sigma_{0} / E_{0}\right), E_{0}=E_{c}$ is the elastic modulus of concrete. The stress-strain relationship of concrete in tension was assumed to be linear up to the uniaxial tensile strength. For the tension softening part, the relation was determined using the exponential function proposed by Belarbi and Hsu [21-22] as shown in Eqs. (3)-(4): 


$$
\begin{aligned}
& \sigma=\mathrm{E}_{c} \varepsilon \text { if } \varepsilon \leq \varepsilon_{t} \\
& \sigma=\sigma_{t}\left(\frac{\varepsilon_{t}}{\varepsilon}\right)^{0.4} \text { if } \varepsilon>\varepsilon_{t}
\end{aligned}
$$

where $\sigma_{t}=0.33 \sqrt{f_{c}^{\prime}}(M P a)$ are the tensile strength of concrete [21] and the corresponding strain, $\varepsilon_{t}=\sigma_{t} / E_{c}$. The internal and external reinforcement and anchorage steel in this study were modeled as elastic-perfectly plastic material with Poisson's ratio $v=0.3$. The modulus of elasticity for the anchorage steel was considered to be 10 times higher than for normal steel to prevent deflection during the analysis.

\subsection{Prestressing rods}

ABAQUS allows direct application of prestress in the bar element [18]. In general, the prestressing effect in ABAQUS is modeled in two different ways: (1) initial stress and (2) initial temperature load [18]. In this research, prestress was applied in external rods by defining an initial stress condition.

\section{FEA Results and Discussions}

\subsection{Validation of the FE model}

The FE model of the tested specimen was verified with experimental results in terms of load-to-midspan deflection and damage behavior and damage distribution at the diagonal shear failure and ultimate shear failure stages. The force-midspan deflection curves obtained from FEA and the experimental testing are shown in Fig. 16. The response obtained from FEA was slightly stiffer in the initial stages which may have occurred because of the effects of some presupposed variables such as the choice of tensile and compressive constitutive models or the uncertainties involved with experimental efforts like the probable existence of material deficiencies. However, the response obtained from the FEA showed excellent agreement with the results obtained from the experimental test in the diagonal shear failure and ultimate loading stages. During the experiment, the diagonal shear failure and ultimate shear failure of the SB1 beam specimen occurred when the midspan deflections were at $7.69 \mathrm{~mm}$ and $8.77 \mathrm{~mm}$, respectively. The shear capacities of the beam specimen corresponding to these displacements during the tests were $290.19 \mathrm{kN}$ and $311.56 \mathrm{kN}$, respectively. The midspan deflections corresponding to these loads in the FE model were 7.63 and $9.16 \mathrm{~mm}$, respectively. The displacement in the FE model at the first shear failure load was less by $0.78 \%$, whereas, for the ultimate failure load, it was $4.45 \%$ higher than that of the experimental results.

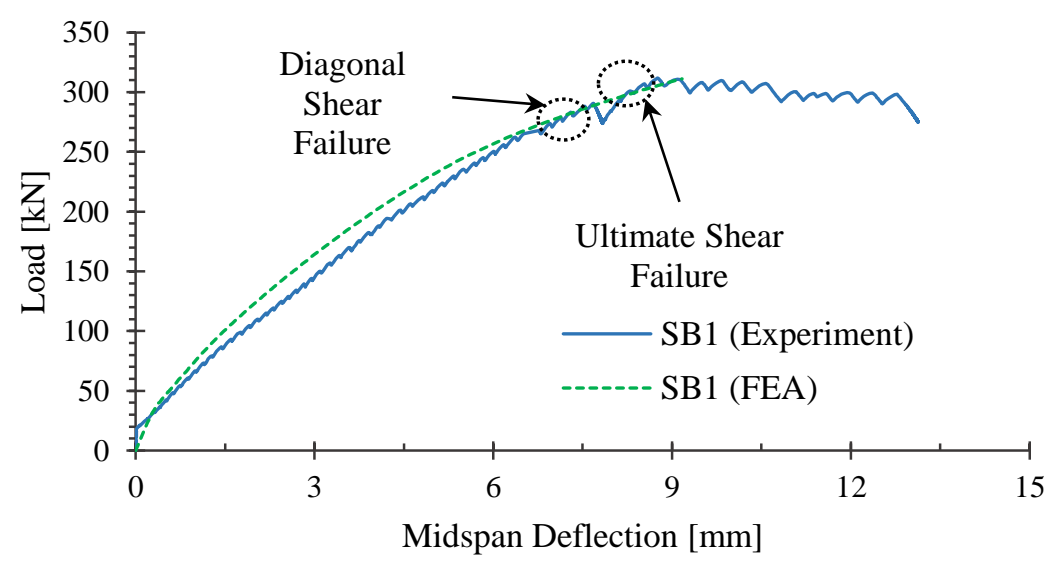

Fig. 16 Load versus midspan deflection in SB1

\subsection{Model behavior and failure patterns}

The CDP model in ABAQUS simulates the nonlinear behavior of concrete both in tension and compression [18]. Therefore, the model behavior, especially regarding the concrete tensile and compressive damage or crack patterns and the concrete strain in the shear region, were additionally observed to validate the accuracy of the FE model. 
Fig. 17(a) shows the damage pattern, running from the loading point to the supports, occurred during the experimental test, on a face of beam specimen SB1. Damages that occurred in the corresponding faces in the FE model in the ultimate failure load stage are displayed in Fig. 17(b) in terms of the Equivalent Plastic Strain (PEEQ). The damage distribution demonstrated by the FE model matched with the nonlinear damage distribution attributed by experimentally tested beam specimens. Fig 17(c) represents the crack pattern of concrete based on the maximum principal plastic strain which is the main indicator of concrete cracking in the CDP model. The concentrations of maximum principal plastic strain, displayed in Fig. 17(c) and (d), also matched with the diagonal shear crack that occurred during the experimental test. Fig. 17(d), in addition, shows the concentration, directions, and magnitudes of cracks. The directions of the cracks observed in the experimentally tested beam specimen were perpendicular to the directions of the maximum principal plastic strain in Fig. 17(d), confirming the guideline provided in ABAQUS manual. In overall, the FE model replicated the damage pattern demonstrated by the experimental tests.

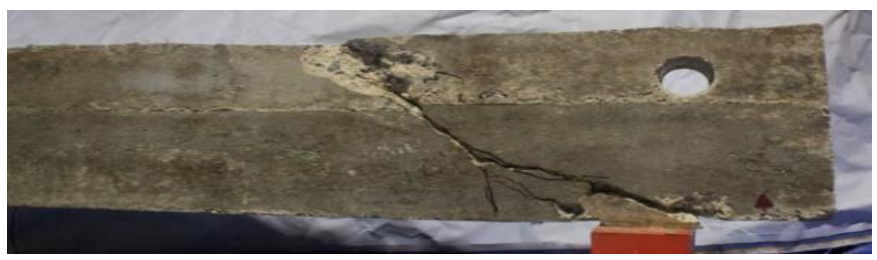

(a) Crack patterns and damage in SB1 during the experiment

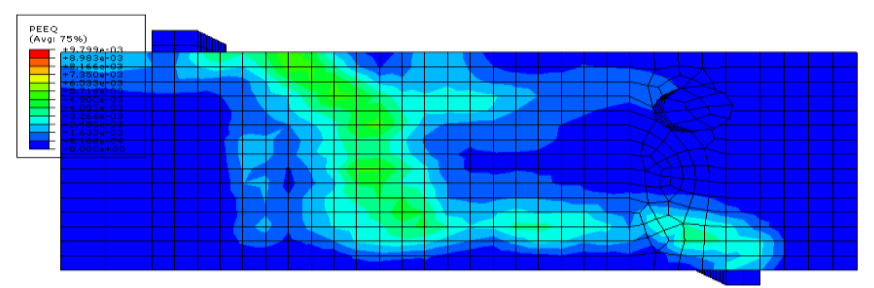

(b) Crack patterns and damage distribution in the FE model (PEEQ)

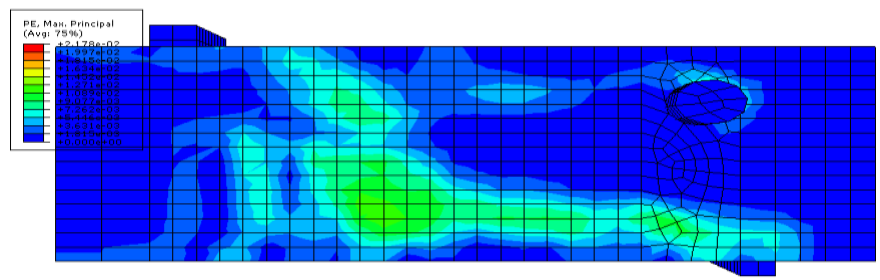

(c) Diagonal cracking development in FE model (Maximum principal plastic strain)

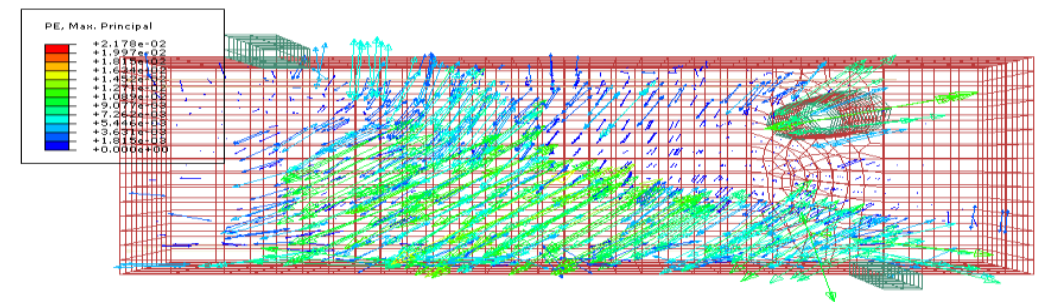

(d) Direction, concentration, and magnitude of maximum principal plastic strain in the FE model

Fig. 17 Comparison of concrete failure patterns in the experimental test with FEA results at the ultimate loading stage

During the experiment, the beam specimens failed in shear by crushing of concrete in the vicinity of the loading point. In order to observe the strain distribution in compression zone, the axial strain of concrete at every $100 \mathrm{~mm}$ distance from the support to the loading point and at the midspan (axis of symmetry) were observed for three loading stages: load equal to $50 \mathrm{kN}$, load equal to $189.84 \mathrm{kN}$ (diagonal shear failure), and load equal to $311.56 \mathrm{kN}$ (ultimate failure load). The average strain at a particular depth of section was calculated by taking mean values from the nodal points of all elements. The locations of the sections in which the axial strains were measured are shown in Fig. 18(a). Figs. 18(b)-(f) represent the distribution of axial strains along with the depth of section at every $100 \mathrm{~mm}$ from the support, whereas Fig. 18(g) shows the strain distribution at the midspan. When the applied load was equal to $50 \mathrm{kN}$, the strains in all sections were relatively low, and the neutral axis depths 


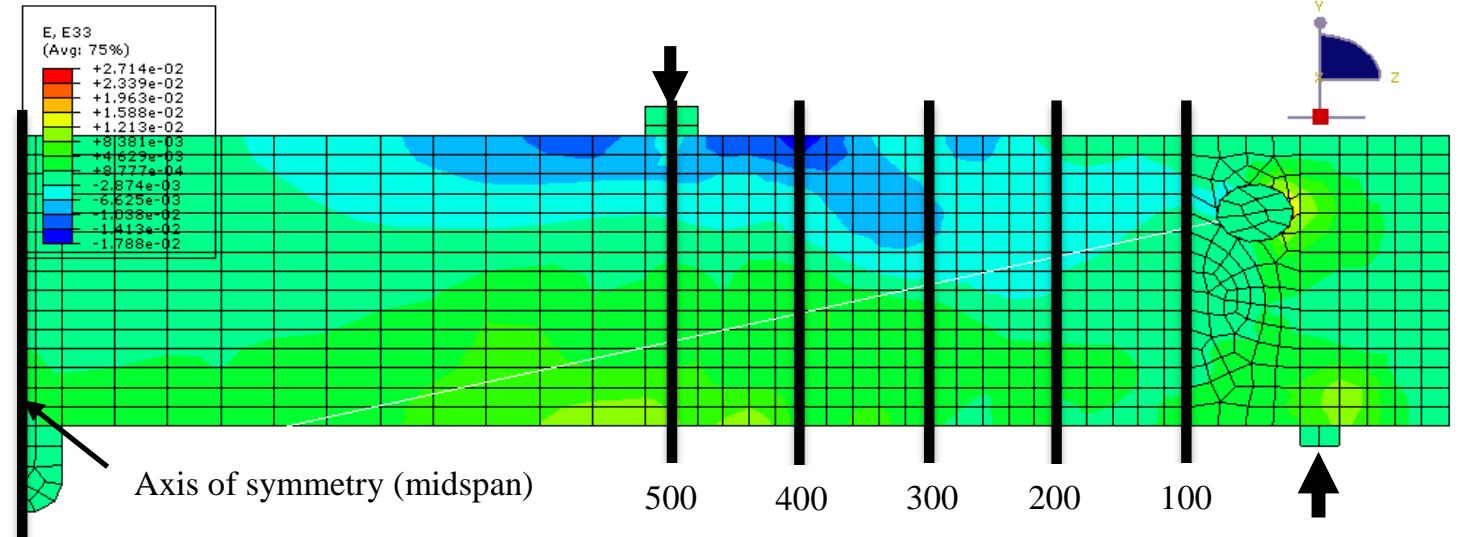

(a) Locations of sections selected for strain measurements

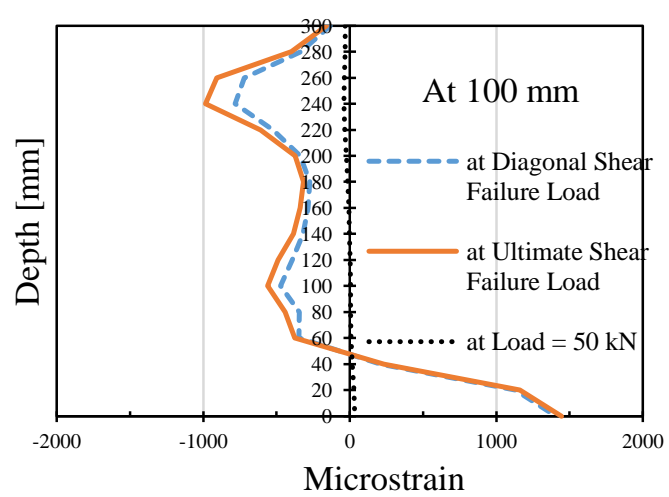

(b) at $100 \mathrm{~mm}$

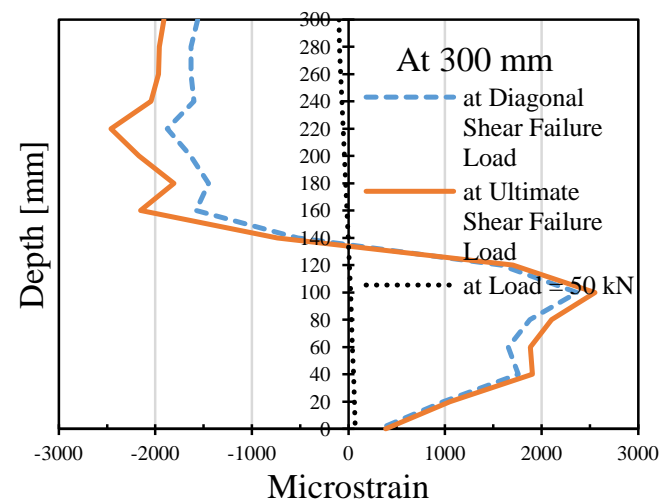

(d) at $300 \mathrm{~mm}$

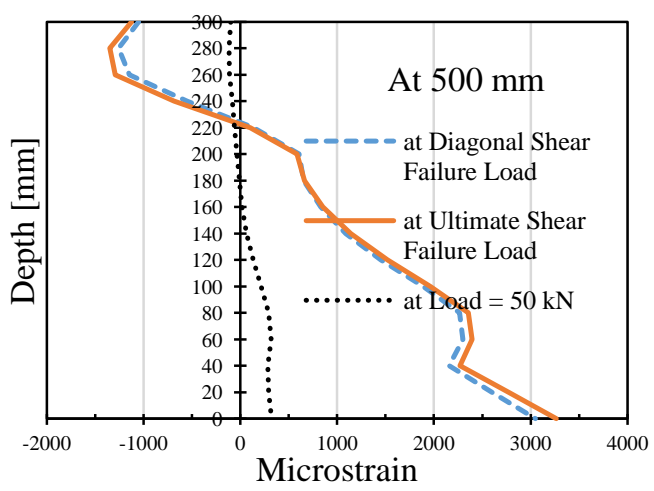

(f) at $500 \mathrm{~mm}$

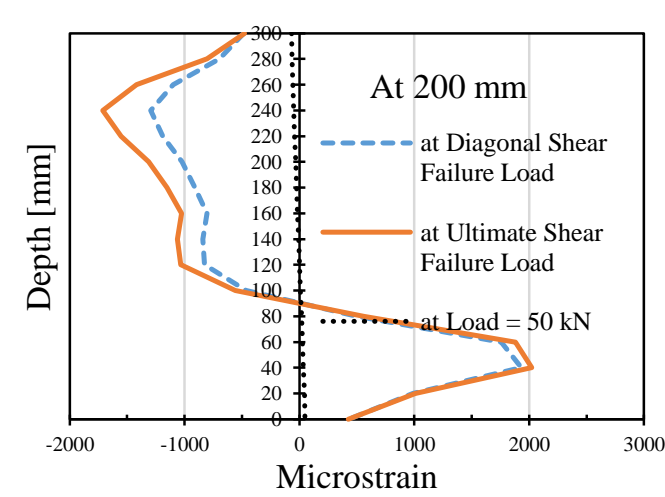

(c) at $200 \mathrm{~mm}$

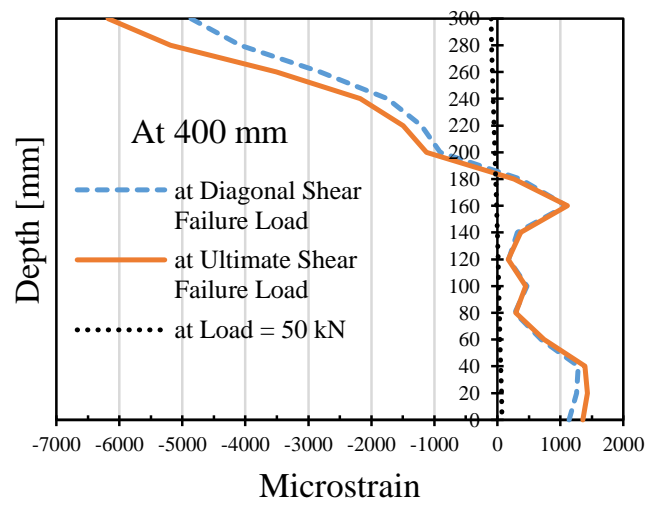

(e) at $400 \mathrm{~mm}$

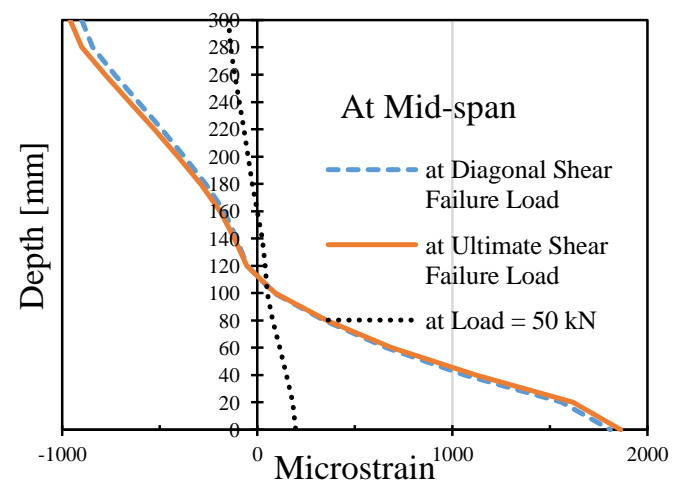

(g) at mid-span

Fig. 18 Concrete strain distribution and neutral axis depth variations along with the section height of SB1

were close to the mid-depth. At diagonal shear failure, the compressive strain at the top $40 \mathrm{~mm}$ portion of the concrete at section $400 \mathrm{~mm}$ exceeded 0.0035 , while the strains on rest sections were below 0.002 . The neutral axis depth from the top fiber 
decreased on moving from the support to the loading point and gradually increased thereafter until the midspan. In the ultimate loading stage, the maximum concrete strains at the section $300 \mathrm{~mm}$ exceeded the value 0.002 , between the depth of 60 and 100 $\mathrm{mm}$, with the maximum 0.0025 at $80 \mathrm{~mm}$ depth, from the top fiber. At this stage, the top fiber of the concrete at $400 \mathrm{~mm}$ had the maximum compressive strain value of 0.0062 . The axial strain at this section above $60 \mathrm{~mm}$ depth was higher than 0.0035 . At the mid-span section, the maximum compressive strain in the ultimate load stage was 0.0009 and the maximum tensile strain was less than 0.0018. Thus, there was the validation that similar to the experimental test, the concrete in the FE model began to crush in the vicinity of the loading point and the compression strut traveled diagonally toward the support.

\subsection{Tensile stress in external posttension rod}

A primary objective of performing the FEA of the tested beam specimens was to numerically capture the value of stress in the external rod. At the diagonal shear failure loading stage, the total stress in the external rod obtained from the FEA was $274.83 \mathrm{MPa}$ (0.55fEPTy). At this loading stage, the average value of stress obtained from the experimental test was 151.58 MPa (0.30fEPTy). The overestimation of stress in FEA was mainly due to the lack of slip among the anchorage and the concrete contact-surfaces. In the experimental test, the anchorages could rotate, keeping the external rods straight throughout the loading, while in FEA, the contact surfaces were constrained. A theoretical approach to compute the stress in the external rod is discussed in Section 6 and compared with the results obtained from the experimental test and FEA.

\section{Theoretical Analysis: Computation of Shear Strength of EPT Beam}

\subsection{Structural analysis of beam specimen}

The analytical solution of the simply supported beam strengthened using a $\mathrm{V}$-shaped external rod system was based on the loading details shown in Fig. 19, where the vertical upward reactions at the end supports are equal to 0.5P(V). The computation of shear capacity in this study was carried out at the loading stage of diagonal shear failure.

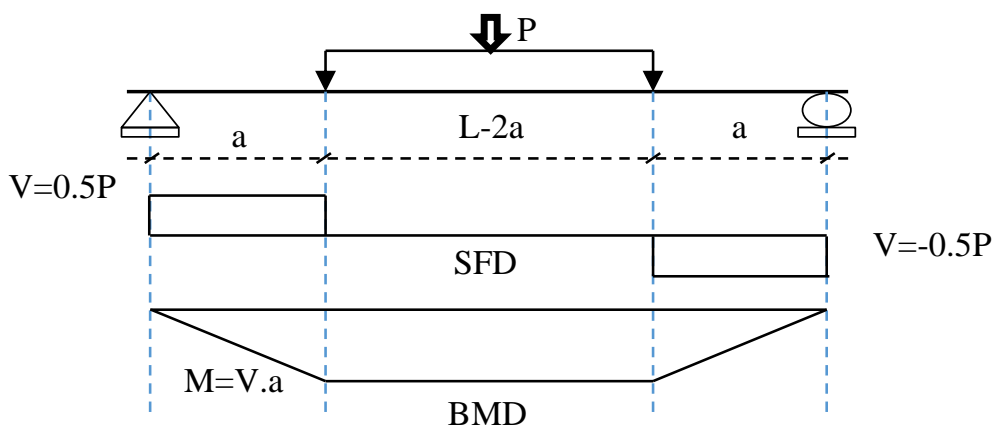

Fig. 19 Shear force and bending moment diagram of the analytical beam

\subsection{Computation of nominal shear strength}

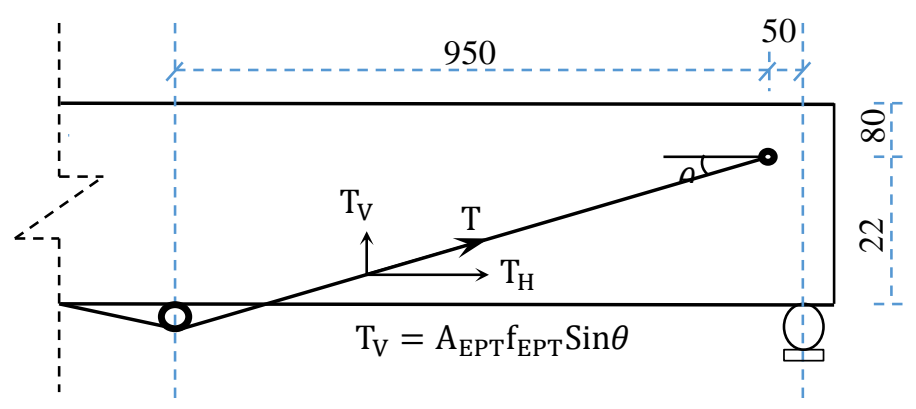

Fig. 20 Vertical force component contributing to shear strengh

As the beams used in this research were deep beams, the STM method was used to calculate the strength of the RC deep beam by following the recommendations in ACI 318-14. The shear strength of the external rod was computed using 
load-to-midspan deflection relationship. The shear capacity of the strengthened beam along with external posttension rods was then calculated using Eq. (5), in which the strength contributed by external rod is calculated by using the vertical component of tensile stress in the rod, as shown in Fig. 20.

$$
V_{n}=V_{S T M}+V_{E P T}
$$

where $V_{S T M}$ is the nominal shear strength of the deep RC beam and $V_{E P T}$ is the nominal shear strength of the external posttension rod.

\subsubsection{Nominal shear strength of RC deep beam using $\operatorname{STM}\left(V_{S T M}\right)$}

A simple form of STM is shown in Fig. 21. The external force applied from the upper plate is transferred to the supports through the compression struts and the reinforcements, or the ties which act as the tensile members, of the truss. The STM adopted in this research is presented in Fig. 22. Such a model of STM satisfying the force equilibrium are developed from beam dimensions, reinforcement detailing, material properties, and testing parameters. The minimum value of the strengths of the diagonal strut at the bottom $V_{s A}$ and at the top $V_{s B}$, the strength of diagonal strut at the midlength $V_{m s}$, the strengths of the nodal zone at the bottom $V_{n s A}$ and at the top $V_{n s B}$, and the yielding strengths of tension ties $V_{t y}$ is considered as the nominal shear strength of the RC deep beam:

$$
V_{S T M}=\min \left\{V_{s A}, V_{s B}, V_{m s}, V_{n s A}, V_{n s B}, V_{t y}\right\}
$$

Further, the strengths of the struts are multiplied by the efficiency factors $0.85 \beta_{s}$, where the value of $\beta_{s}$ depends on the amount of horizontal and vertical reinforcements crossing the strut, and the strengths of the nodal zones are determined by using nodal efficiency factor $\beta_{n}$ for nodes [23].

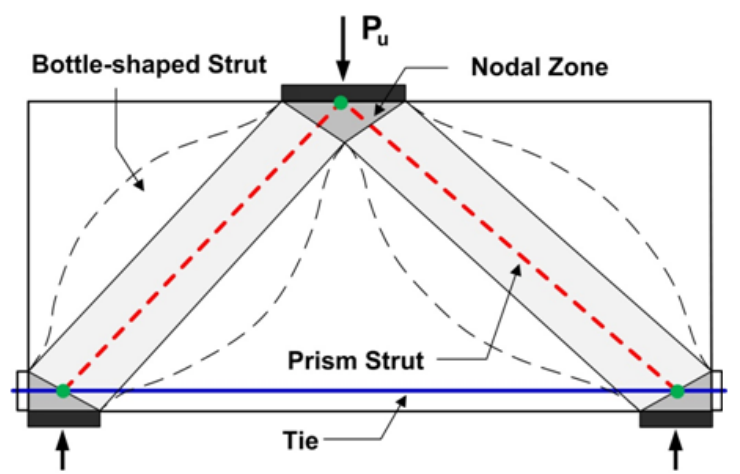

Fig. 21 Representation of components of the truss model in STM

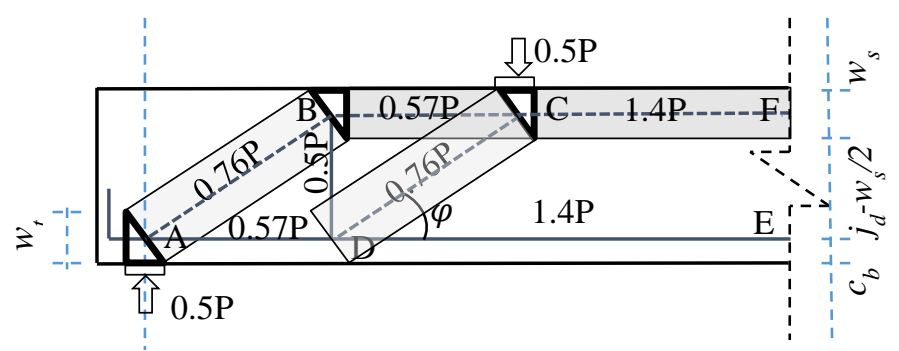

Fig. 22 Internal load transfer in CB in terms of STM

The dimensions of the upper horizontal strut represent the flexural stresses block in the beam and can be evaluated from the equilibrium of external and internal moments, as written in Eq. (7):

$$
w_{s}=\left(A_{s} f_{y}\right) /\left(0.85 \beta_{s} f_{c}^{\prime} b\right)
$$


where $A_{s} f_{y}$ represents the yielding strength of the main flexural reinforcement, $f_{c}^{\prime}$ is the compressive strength of concrete, and $b$ is the width of the beam. Similarly, according to ACI 318-14, the width of the tie for a single-layered reinforcement can be calculated using Eq. (8):

$$
w_{t}=2 C_{b}
$$

where $C_{b}$ is the concrete cover. The inclination of the compression strut relative to the horizontal axis is computed using Eqs. (9)-(10):

$$
\begin{aligned}
& \varphi=\arctan \left(j_{d} / a\right) \\
& j_{d}=h-w_{s} / 2-w_{t} / 2
\end{aligned}
$$

where $j_{d}$ is the lever arm of the resultant flexural forces, $a$ is the shear span, $h$ is the depth of the beam. After calculating the above parameters, the widths of struts at midlength and at nodal zone calculated using Eqs. (11)-(12):

$$
\begin{aligned}
& w_{s A}=w_{n s A}=\min \left\{\sqrt{w_{t}^{2}+l_{b}^{2}}, \quad\left(w_{t} \cos \varphi+l_{b} \sin \varphi\right)\right\} \\
& w_{s B}=w_{n s B}=\min \left\{\sqrt{w_{s}^{2}+l_{p}^{2}}, \quad\left(w_{s} \cos \varphi+l_{p} \sin \varphi\right)\right\}
\end{aligned}
$$

where $l_{p}$ and $l_{b}$ are widths of support and loading plates, respectively.

\subsubsection{Nominal shear strength of external posttension $\operatorname{rod}\left(V_{E P T}\right)$}

The shear strength contributed by the external rods can be computed based on the geometric orientation of the external rods. As shown in Fig. 20, the vertical component of the tensile force generated in the external rod, on the application of the vertical load, along with the initial prestressing force provide the shear strength for the external rods. Therefore, the shear strength of the external rods can be computed using Eq. (13):

$$
V_{E P T}=2 A_{E P T}\left(f_{\text {intial }}+\Delta f_{E P T}\right) \operatorname{Sin} \theta
$$

where $A_{E P T}$ is the cross-sectional area of the external rod, $f_{\text {initial }}$ is the initial stress applied on the external rod, $\Delta f_{E P T}$ is the tensile stress generated on the external rod on the application of the loading, and $\theta$ is the inclination of the steel rod with respect to the horizontal direction.

\subsection{Computation of stress in external rod $\left(f_{E P T}\right)$}

Several equations have been proposed to calculate the stress of the unbonded tendon [24-27] at flexural failure stages. ACI 318-11 also provides an equation to calculate stress in unbonded tendons at the nominal flexural failure stage. However, the available equations do not refer to the shear failure stages and thus were not adopted in this investigation. Instead, an attempt was made to calculate the stress in unbonded rods using the relationship between midspan deflection and stress in the external rod.

In Eq. (13), the stress generated in the external rod was unknown as the steel rod did not yield in the diagonal shear failure stage. The generated stress in the external rod can be predicted using the load-midspan deflection relationship considering that the unbonded rod acts similarly to an RC deep beam in the service load stage [28]. For simplification of the calculations, the following assumptions were not considered in this research: axial shortening of the beam due to prestressing force, changes in the location of end anchorages, and friction at the deviators and anchorages. 
The compatibility condition for the analysis was considered at the midspan of the strengthened beam, at which point the vertical deflections of the beam and the external rod are equal $[2,16]$. The tensile stress in the external rod was then computed by calculating the deflection of the unreinforced beam at the mid-span during the diagonal shear failure followed by the computation of strain in the external rods. The procedure to compute the stress is summarized below:

When an unreinforced (unreinforced with EPT) section fails in shear, the vertical shear force acting on the section, V, is expressed in Eqs. (14)-(15):

$$
\begin{aligned}
& V=V_{S T M} \\
& P_{R C-V}=2 V_{S T M}
\end{aligned}
$$

where $P_{R C-V}$ is the total vertical load acting on the beam. Assuming the specimen is in the elastic region at the diagonal shear failure, the midspan deflection of the unreinforced beam is obtained from the loading configuration and effective moment of inertia Eq. (16):

$$
\Delta_{\text {mid }}=\frac{K}{E_{c} I_{e}} P_{R C-V}
$$

where $K=\frac{a}{24}\left(3 L^{2}-4 a^{2}\right)$ is the value depending on the loading detail and boundary condition $\left(\mathrm{mm}^{3}\right)$ and $I_{e}$ is the effective moment of inertia $\left(\mathrm{mm}^{4}\right)$. Similarly, the effective moment of inertia for a simply supported beam was calculated from its cracked section using Eq. (17):

$$
\mathrm{I}_{e}=\left(\frac{M_{c r}}{M_{a}}\right)^{3} I_{g}+\left[1-\left(\frac{M_{c r}}{M_{a}}\right)^{3}\right] I_{c r} \leq I_{g}
$$

where $I_{c r}$ is the moment of inertia of the cracked section, $I_{g}$ is the moment of inertia of the gross section, $M_{c r}$ is the cracking moment, and $M_{a}$ is the moment at the desired section. It is to be noted that the midspan deflection was calculated given the fact that the clear span-to-depth ratio $\left(\mathrm{L}_{\mathrm{c}} / \mathrm{h}\right)$ of the beam specimens were $6.5(>4)$ and that the short-term deflection obtained using cracked section stiffness provides satisfactory result for RC deep beams with $\mathrm{a} / \mathrm{h}>1$ [29]. Assuming that the specimen is symmetric, the concrete has sufficient bearing strength, and the bottom-anchorage has sufficient stiffness preventing it from any kinds of deflections, the midspan deflection of the beam and external rod are equal [2, 16]. Therefore, the vertical deflection of the EPT rod at the mid-span is equal to the vertical deflection of the RC beam as provided in Eq. (18):

$$
\Delta_{\text {mid }}=\Delta_{E P T}=\Delta_{\mathrm{B}}
$$
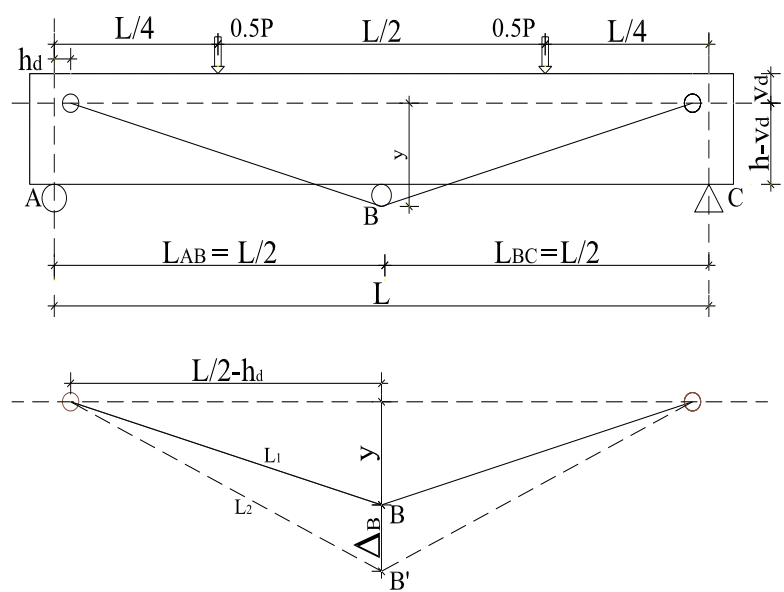

Fig. 23 Deflected shape of the external prestressing rod due to external loading 
By using the deflected shape of the posttension rod due to the external loading as shown in Fig. 23, the change in length and strain in the external rod can be calculated Eqs. (19)-(21):

$$
\begin{aligned}
& L_{1}=\sqrt{\left(L / 2-h_{d}\right)^{2}+y^{2}} \\
& L_{2}=\sqrt{\left(L / 2-h_{d}\right)^{2}+\left(y+\Delta_{B}\right)^{2}} \\
& \Delta \varepsilon_{E P T}=\frac{L_{2}-L_{1}}{L_{1}}
\end{aligned}
$$

where $y$ is the depth of the external posttension from the anchorage pin, $h_{d}$ is the horizontal distance between the support and anchorage pin. The generated stress $\left(\Delta f_{E P T}\right)$ on the external rod was computed by multiplying the strain by the elastic modulus of the steel rod, as shown in Eq. (22) and the total tensile stress acting on the external rod was computed by adding the generated stress with the initial prestress ( $\left.f_{\text {initial }}\right)$ as shown in Eq. (23):

$$
\begin{aligned}
& \Delta f_{E P T}=\Delta \varepsilon_{E P T} E_{E P T} \\
& f_{E P T}=f_{\text {initial }}+\Delta f_{E P T}
\end{aligned}
$$

\subsection{Comparison of theoretically computed stress with FEA result}

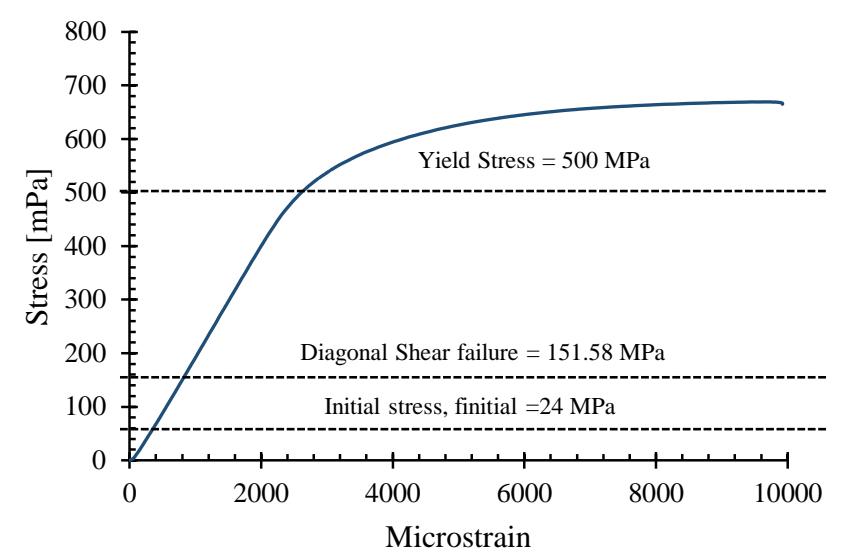

Fig. 24 Stress in the external rod at various stages during experimental test

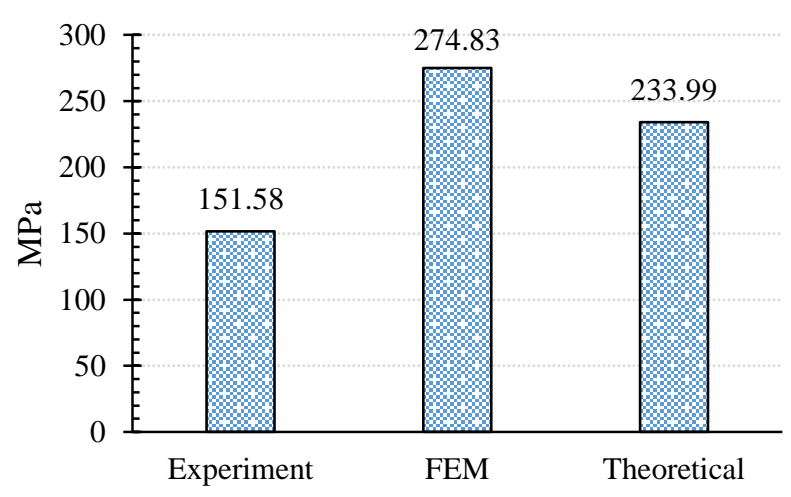

Fig. 25 Comparison of theoretically computed stress with FEA and experiment result at diagonal shear failure

The theoretical value of tensile stress generated in the external rod at the diagonal shear failure was determined using Eqs. (19)-(21). The stress in the external rod at various stages of loading during the experimental test are shown in Fig. 24 and the comparison of the stress obtained from the theoretical approach with experimental test and FEA is shown in Fig. 25. The total stresses obtained experiment, FEA, and Eq. (23) at diagonal shear failure stage were 151.58, 274.83, and 233.99 MPa. The 
ratio of stress computed theoretically to experiment and FEA results were 1.54 and 0.85 , respectively. The non-uniform distribution of stress, allowance of slip, and losses associated with factors such as losses in anchors and turnbuckles may have resulted in lower stress value during the experimental test.

\subsection{Prediction of nominal strength of EPT beam}

The total shear capacity of the un-strengthened beam at the diagonal shear failure was computed using STM, recommended in ACI 318-14, and the shear strength of the external rod was determined from Eq. (13). The nominal shear strength of the beam was then calculated by adding the strength of the external rod with the strength of RC deep beam. The comparison between the shear capacities obtained from hence is shown in Fig. 26, and the numerical values are provided in Table 3. The shear capacity obtained theoretically and experimentally were 318.91 and $290.19 \mathrm{kN}$, respectively, resulting in their ratio of 1.10. Thus, based on the experimental test, FEA, and theoretical analysis, the stress in the external rod and the nominal shear strength of the RC beam strengthened using a V-shaped external rod system were computed. The theoretically approximated shear strength at the diagonal shear failure stage was within the limit of 1.10 compared to the experimental test result. The parameters affecting the stress in the external rod and overall shear strength of the beam will be investigated further through the FE model.

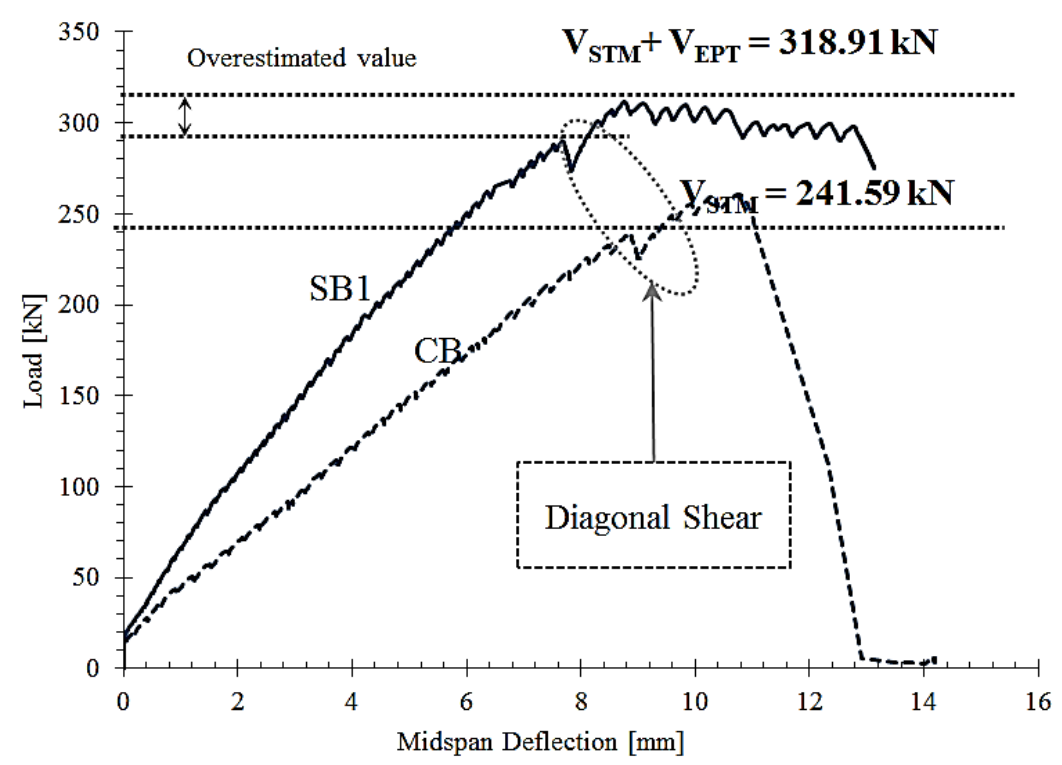

Fig. 26 Comparison of theoretically computed stress with FEA and experiment result at diagonal shear failure

Table 3 Shear Strength Comparison of Experimental Result with Theoretical Equation

\begin{tabular}{|c|c|c|c|c|c|}
\hline \multirow{2}{*}{ Beam Specimen } & $\mathrm{P}_{\mathrm{STM}}$ & $\mathrm{P}_{\mathrm{EPT}}$ & $\mathrm{P}_{\text {Theoretical }}$ & $\mathrm{P}_{\text {Experimental }}$ & \multirow{2}{*}{$(1) /(2)$} \\
\cline { 2 - 5 } & {$[\mathrm{KN}]$} & {$[\mathrm{KN}]$} & {$[\mathrm{KN}](1)$} & {$[\mathrm{KN}](2)$} & \\
\hline $\mathrm{CB}$ & 241.59 & - & 241.56 & 239.14 & 1.01 \\
\hline SB1 & 241.59 & 77.32 & 318.91 & 290.61 & 1.10 \\
\hline
\end{tabular}

\section{Conclusions}

The effect of a V-shaped external rod system on the shear behavior of a strengthened RC deep beam specimen was investigated through experimental testing. The structural behavior of the EPT beam in shear was investigated based on the load-to-midspan deflection relationship, ultimate load carrying capacity, stiffness, ductility, and failure mode. The tested beam was simulated using FEM based software, ABAQUS. The simulated FE model was validated based on the load-to-midspan relationship, crack pattern and damage distribution, and strain distribution along the shear region. The tensile stress on the external rod was obtained using a theoretical approach and compared with the experimental test and FEA results. Finally, the nominal shear strength of the strengthened beam was computed and compared with the experimental result at the diagonal shear failure. The main conclusions drawn from the research were as follows: 
(1) The application of V-shaped external rod in RC deep beam delayed the initiation of diagonal shear cracks, decreased in the inclinations of critical shear cracks, and improved of load carrying capacities by $21 \%$ and $20 \%$ at diagonal shear and at ultimate shear failure stage, respectively.

(2) The failure mechanism of the RC beam shifted to shear ductile failure from shear brittle failure upon the application of a V-shaped external rod.

(3) The strain distribution based on FEA showed that with an increase in the applied load, the neutral axis depth from the top fiber of concrete decreased on moving from the support to the loading point and increased until the midspan and thereafter. Thus, the failure mode of the strengthened beam was most likely to occur by the crushing of the concrete in the vicinity of the loading point, where the depth of the concrete to withstand the compressive stress is lowest.

(4) The stress obtained from theoretical approach was relatively close to FEA than the experimental test result. The non-uniform distribution of stress, allowance of slip, and losses associated with various factors such as losses in anchors and turnbuckles may have resulted in lower value of stress during the experimental test.

(5) The ratio of the nominal shear strength obtained from the theoretical approach to the experimental test was 1.10 , indicating that the method discussed in this research could approximate the shear strength at the diagonal shear failure.

\section{Acknowledgment}

We are grateful to the Faculty of Engineering, Kasetsart University, Bangkok, Thailand for providing financial support to conduct this research. We also express our gratitude to the Department of Civil Engineering, Kasetsart University, Bangkhen campus, for facilitating this research works.

\section{Conflicts of Interest}

The authors declare no conflict of interest.

\section{References}

[1] M. H. Harajli, "Strengthening of concrete beams by external prestressing," PCI Journal, vol. 38, no. 6, pp. 76-88, December 1993.

[2] K. J. Shin, J. H. Lim, Y. S. Oh, and J. H. Moon, “An experimental study on the flexural behavior of RC beams strengthened with high-strength bars," Magazine of Concrete Research, vol. 59, no. 7, pp. 469-481, September 2007.

[3] K. J. Shin and S. H. Lee, "Flexural behavior of RC beams strengthened with a high-tension steel rod," Magazine of Concrete Research, vol. 62, no. 2, pp. 137-147, February 2010.

[4] K. J. Shin, S. H. Lee, and T. H. K. Kang, "External posttensioning of reinforced concrete beams using a V-shaped steel rod system,” Journal of Structural Engineering, vol. 140, no. 3, pp. 04013067, March 2014.

[5] M. I. Ary and T. H. K. Kang, "Shear-strengthening of reinforced \& prestressed concrete beams using FRP: part I-review of previous research,” International Journal of Concrete Structures and Materials, vol. 6, pp. 41-47, 2012.

[6] T. H. K. Kang and M. I. Ary, "Shear-strengthening of reinforced \& prestressed concrete beams using FRP: part II-Experimental investigation,” International Journal of Concrete Structures and Materials, vol. 6, pp. 49-57, 2012.

[7] S. Aykac, I. Kalkan, B. Aykac, S. Karahan, and S. Kayar, "Strengthening and repair of reinforced concrete beams using external steel plates,” Journal of Structural Engineering, vol. 139, no. 6, pp. 929-939, September 2012.

[8] H. Rodrigues, P. Pradhan, A. Furtado, P. Rocha, and N. Vila-Pouca, "Structural repair and strengthening of RC elements with concrete jacketing," Strengthening and Retrofitting of Existing Structures, Springer, pp. 181-198, 2018.

[9] R. Kotynia, "Debonding Phenomena in FRP-Strengthened Concrete Members," in Proc. Brittle Matrix Composites 8, 2006, pp. 109-122.

[10] R. Barnes, P. Baglin, G. Mays, and N. Subedi, "External steel plate systems for the shear strengthening of reinforced concrete beams," Engineering Structures, vol. 23, no. 9, pp. 1162-1176, September 2001.

[11] B. B. Adhikary and H. Mutsuyoshi, "Shear strengthening of reinforced concrete beams using various techniques," Construction and Building Materials, vol. 20, no. 6, pp. 366-373, July 2006.

[12] S. H. Lee, K. J. Shin, and H. D. J. A. S. Lee, "Post-tensioning steel rod system for flexural strengthening in damaged reinforced concrete beams," Applied Science, vol. 8, no. 10, pp. 1763, September 2018. 
[13] F. Au and J. Du, "Prediction of ultimate stress in unbonded prestressed tendons," Magazine of Concrete Research, vol. 56, no. 1, pp. 1-11, February 2004.

[14] Z. Q. He and Z. Liu, "Stresses in external and internal unbonded tendons: unified methodology and design equations," Journal of Structural Engineering, vol. 136, no. 9, pp. 1055-1065, February 2010.

[15] S. Sirimontree, B. Witchayangkoon, N. Khaosri, and J. Teerawong, "Shear strength of reinforced concrete beam strengthened by transverse external post-tension," American Journal of Engineering and Applied Sciences, vol. 4, no. 1, pp. 108-115, 2011.

[16] S. Lee, U. Yeo, K. Shin, and W. Kim, “Analytical study on strengthening effect of RC beams strengthened with high-tension steel rod," presented at the Structures Congress 2010, 2010.

[17] T. C. Zsutty, "Beam shear strength prediction by analysis of existing data," Journal Proceedings, vol. 65, no. 11, pp. 943-951, November 1968.

[18] Abaqus Users Manual, Version 6.13-2, Dassault Systémes Simulia Corp., Providence, Rhode Island, USA, 2013.

[19] W. Ren, L. H. Sneed, Y. Yang, and R. He, "Numerical simulation of prestressed precast concrete bridge deck panels using damage plasticity model," International Journal of Concrete Structures and Materials, vol. 9, no. 1, pp. 45-54, March 2015.

[20] E. Hognestad, "Study of combined bending and axial load in reinforced concrete members," University of Illinois at Urbana Champaign, College of Engineering, 1951.

[21] A. Belarbi and T. T. Hsu, "Constitutive laws of concrete in tension and reinforcing bars stiffened by concrete," Structural Journal, vol. 91, no. 4, pp. 465-474, July 1994.

[22] X. B. D. Pang and T. T. Hsu, "Behavior of reinforced concrete membrane elements in shear," Structural Journal, vol. 92, no. 6, pp. 665-679, November 1995.

[23] Building Code Requirements for Structural Concrete, ACI 318-14, ACI Standard, 2014.

[24] A. E. J. S. P. Naaman, "New methodology for the analysis of beams prestressed with external or unbonded tendons," American Concrete Institute, vol. 120, pp. 339-354, June 1990.

[25] A. E. Naaman, N. Burns, C. French, W. L. Gamble, and A. H. J. S. J. Mattock, "Stresses in unbonded prestressing tendons at ultimate: recommendation," Structural Journal, vol. 99, pp. 518-529, July 2002.

[26] M. H. Harajli and S. A. J. P. J. Hijazi, "Evaluation of the ultimate steel stress in partially prestressed concrete members," PCI Journal, vol. 36, no. 1, pp. 62-82, February 1991.

[27] M. H. J. S. J. Harajli, "Effect of span-depth ratio on the ultimate steel stress in unbonded prestressed concrete members," American Concrete Institute, vol. 87, no. 3, pp. 305-312, May 1990.

[28] R. Manisekar and R. Senthil, "Stress at ultimate in unbonded post tensioning tendons for simply supported beams: a state-of-the-art review," Advances in Structural Engineering, vol. 9, pp. 321-335, 2006.

[29] P. Kumar, "Short-Term deflection of deep beams," Journal Proceedings, vol. 75, no. 8, pp. 381-383, August 1978.

Copyright $($ by the authors. Licensee TAETI, Taiwan. This article is an open access article distributed under the terms and conditions of the Creative Commons Attribution (CC BY-NC) license (https://creativecommons.org/licenses/by-nc/4.0/). 